\title{
Naloxone reduces fluid consumption: Relationship of this effect to conditioned taste aversion and morphine dependence
}

\author{
MING-FUNG WU, SARA E. CRUZ-MORALES, JAY R. QUINAN, \\ JUNE M. STAPLETON, and LARRY D. REID \\ Rensselaer Polytechnic Institute, Troy, New York 12181
}

\begin{abstract}
Naloxone reduces fluid consumption in rats. It also produces a conditioned taste aversion (CTA). No reliable correlation was found between these two measures, suggesting that the reductions in drinking are unrelated to the illness-producing effects indexed by the CTA test. Measures of CTA using naloxone were also uncorrelated with measures of voluntary oral consumption of sweetened morphine solutions. In addition, naloxone suppression of drinking was unaffected by prior morphine administration with the administration of morphine given in a variety of ways, including dependence-producing regimens of injections.
\end{abstract}

This report is an addendum to Gorman, DeObaldia, Scott, and Reid (1978) and to Stapleton, Ostrowski, Merriman, Lind, and Reid (1979). Gorman et al. found that the extent of conditioned taste aversion (CTA) using morphine injections as the putative unconditioned stimulus was related to the amount of sweetened morphine solution voluntarily taken by rats. There are considerable individual differences among rats in the extent of CTAs using naloxone injections as the unconditioned stimulus, and we wondered whether this differential responsiveness to naloxone might also be related to voluntary intake of morphine solution. The rationale underlying the question involved the possibility that the extent of CTA using naloxone might be related to individual differences in endorphinergic functioning.

Stapleton, Ostrowski, Merriman, Lind, and Reid (1979) verified that naloxone reduced the fluid consumption of water-deprived rats given access to water for brief tests. This reduction in fluid consumption could be due to naloxone blockade of endorphinergic processes, or it could be related to naloxone's ability to produce a nonspecific illness or malaise. If the CTA test indexes the illness-producing effects of naloxune, and if the reductions in fluid consumption are due to such effects, then there should be a significant correlation between these two measures.

\section{EXPERIMENT 1}

Experiment 1 tested for a correlation between the

This work was supported by Grants MH/DA 31987 and BNS 78-17860 to Ralph G. Noble, principal investigator. S. E. Cruz-Morales is on leave from the Universidad Nacional Autónoma de México y becario de CONACYT. J. M. Stapleton is now with the Department of Psychology, University of California at Los Angeles. Naloxone hydrochloride was provided courtesy of Endo Laboratories. extent of CTA under naloxone and the amount of sweetened morphine solution consumed voluntarily, and for a correlation between the CTA under naloxone and suppression of drinking under naloxone.

\section{Method}

Subjects and Apparatus. The subjects were 40 experimentally naive, male rats (Taconic Farms, Sprague-Dawley derived) weighing $200-350 \mathrm{~g}$ at the beginning of the procedures. The rats were individually housed, with food always available and water available as specified. Glass water bottles equipped with ball-point sipping tubes were weighed to an accuracy of $1 \mathrm{~g}$ to measure fluid consumption.

Procedure. Rats were trained to take a daily ration of water in $15 \mathrm{~min} /$ day for 10 days. On Day 11 and every 3rd day thereafter, a .1\% saccharin solution was presented instead of water as the conditioned stimulus of a CTA procedure. The subjects were randomly assigned to two groups to receive a subcutaneous (s.c.) injection of naloxone hydrochloride $(10 \mathrm{mg} / \mathrm{kg})$ or physiological saline in equivalent volume $(1 \mathrm{ml} / \mathrm{kg})$ immediately after the saccharin presentation as putative unconditioned stimulus (UCS). Saccharin solutions were presented five times and were followed by injections each time except the fifth presentation. On intervening days, water was made available for $15 \mathrm{~min} / \mathrm{day}$.

Beginning the day after the fifth CTA test, all rats were presented with sweetened morphine solution for 8 days in their home cages in a two-bottle choice situation, the other bottle containing tap water. The sweetened morphine solution was $10 \%$ sucrose (w/v) in tap water with $.5 \mathrm{mg}$ of morphine sulfate per milliliter of solution. Fresh solutions were prepared and bottles were weighed every $48 \mathrm{~h}$ to determine morphine consumption.

Following the test of voluntary morphine consumption, rats were permitted food and water ad lib for 6 weeks. During this period, two rats were deleted from the study due to illness. The remaining 38 rats were again placed on the same fluiddeprivation schedule, with water available $15 \mathrm{~min} /$ day. After 4 days of this regimen, they were given a sixth CTA test and, 3 days later, a seventh CTA test with the same drug assignments as on the previous CTA tests.

Beginning the day after the last CTA test, rats were injected each day $15 \mathrm{~min}$ before the daily water presentation. On Days 1 , $2,4,5,7$, and 8 , all rats received saline. To test for naloxone 
suppression of drinking, on Day 3, one half the rats were given naloxone hydrochloride $(10 \mathrm{mg} / \mathrm{kg}$, s.c. $)$ and the other half saline, and on Day 6 these treatments were reversed. Assignment to test day was counterbalanced for possible effects of prior treatment. In summary, there were three measures with the same subjects in this experiment: CTA, consumption of sweetened morphine solution, and naloxone suppression of drinking.

\section{Results and Discussion}

The scores of Saccharin Presentations 2-5 (CTA tests after injection) were submitted to a 2 by 4 analysis of variance (ANOVA) having repeated measures with factors of two groups (naloxone or saline as putative UCS) and four trials. The ANOVA yielded $F(1,38)=$ $45.70(p<.001)$ for the factor of group and $F(3,114)=$ $10.27(p<.001)$ for the interaction of Group by Trial, indicating that naloxone did produce a CTA. On the first saccharin presentation, before any injection, the saccharin consumption of the two groups was very similar, $13.4 \mathrm{~g}$ for the naloxone group and $13.5 \mathrm{~g}$ for the placebo group. Across trials, the consumption of the naloxone group steadily declined, while the placebo group's consumption increased. On the fifth CTA test, mean consumption was $9.6 \mathrm{~g}$ for the naloxone group and $18.7 \mathrm{~g}$ for the placebo group. There were considerable individual differences in the extent of the aversion, with rats of the naloxone group drinking from 3 to $16 \mathrm{~g}$ of saccharin solution on the fifth presentation. These individual differences were stable; that is, the rats maintained their relative standings across test days [Kendall's coefficient of concordance, $\left.\mathrm{W}=.74, \chi^{2}(19)=56.24, \mathrm{p}<.001\right]$ for the four tests following naloxone injections.

Both groups consumed morphine solution. There were no significant differences in the amount of morphine consumed between the two groups $[F(1,38)<1]$. There was a good deal of variability, but the amount of sweetened morphine solution consumed was consistent across tests for the rats of the naloxone group [Kendall's $W=.49, \chi^{2}(19)=37.2, p<.01$ ]. In order to test for a relationship between the extent of CTA under naloxone and the amount of sweetened morphine solution consumed, a Spearman rank correlation coefficient was computed for the naloxone group using the mean of CTA Tests 2-5 and the mean of the four measures of consumption of sweetened morphine solution; it yielded tho $=-.03$.

On the sixth CTA test, the rats receiving naloxone drank significantly less saccharin solution than rats receiving a placebo $[\mathrm{t}(37)=2.44, \mathrm{p}<.02]$, in spite of having received an extinction trial on Test 5 . On Test 7, the naloxone group consumed a mean of $10.9 \mathrm{~g}$, compared with $17.9 \mathrm{~g}$ for the placebo group $[\mathrm{t}(37)=$ $5.09, \mathrm{p}<.001$ ]. A Spearman rank correlation between Test 5 and Test 7 yielded rho $=.51 \mathrm{p}<.05$ ).

On the test for naloxone suppression of drinking, the rats that had previously received naloxone on the CTA tests drank less water after a naloxone injection than after a placebo injection $[\mathrm{t}(18)=6.25, \mathrm{p}<.001]$. A similar decrease in water consumption under naloxone was shown by the rats that had previously received placebo in the CTA tests $[t(10)=9.07, p<.001]$. A Spearman rank correlation between the scores of the test for naloxone suppression of drinking and the scores of the CTA on Test 7 for the rats that had received naloxone on Test 7 yielded rho $=.06$. Thus, the individual differences in naloxone suppression of water consumption were not correlated with the stable individual differences in naloxone-induced CTA, suggesting that the suppression of water consumption is not due to the illness-producing effects indexed by the CTA test. There was also no reliable correlation between the extent of naloxone's suppression of drinking and the amount of sweetened morphine solution consumed $($ Spearman's rho $=-.25)$.

\section{EXPERIMENT 2}

As mentioned, naloxone injection leads to reduced water consumption among water-deprived rats. A question we asked is whether a regimen of morphine dosing, sufficient to produce physical dependence or to lead to enhanced consumption of sweetened morphine solutions, would modify naloxone's control of water consumption. We found, as did Holtzman (1979), that experience with morphine did not reliably modify naloxone's reduction of water consumption.

\section{Method}

The subjects were 43 male, albino rats (Taconic Farms, Sprague-Dawley derived) weighing $375-475 \mathrm{~g}$ at the beginning of the procedures. There were three groups of rats, each half exaddict rats and half nonaddict rats. The 24 subjects of Group 1 were selected from a larger pool of 40 subjects on the basis of their consumption of sweetened morphine solution: 12 were high consumers (mean $=76.52 \mathrm{~g}$ ), and 12 were low consumers (mean $=7.13 \mathrm{~g}$ ). The nine rats of Group 2 had previously served as subjects in an experiment testing the effects of morphine addiction on intracranial self-stimulation (Coogle, 1979). Five rats had received heavy doses of morphine (up to $100 \mathrm{mg} / \mathrm{kg}$ per day), and four rats had little experience with morphine (a total of $6 \mathrm{mg} / \mathrm{kg}$ ). The 10 subjects of Group 3 were experimentally naive rats. They were randomly assigned to two subgroups to receive 10 days of daily injections of morphine sulfate $(10 \mathrm{mg} / \mathrm{kg}$, s.c.) or physiological saline in equivalent volume $(1 \mathrm{ml} / \mathrm{kg})$. A similar regimen of morphine injections has been shown to potentiate subsequent consumption of sweetened morphine solution, whereas heavier regimens may not (Stapleton, Lind, Merriman, Bozarth, \& Reid, 1979). At least 2 weeks after the last morphine injection, all three groups were tested for naloxone suppression of drinking using the same procedures as in Experiment 1.

\section{Results and Discussion}

The exaddict rats and the nonaddict rats of all three groups showed reduced water consumption under naloxone (all ts $>2.10$, ps $<.05$ ). Regardless of the dosing regimen employed, exaddict rats showed reductions in drinking under naloxone that were similar to nonaddict rats. These results confirm Holtzman's (1979) 
conclusion that prior morphine administration does not affect naloxone's ability to modify water consumption.

\section{GENERAL DISCUSSION}

Naloxone injections $(10 \mathrm{mg} / \mathrm{kg})$ can sustain a CTA, a finding verifying the conclusion reached by LeBlanc and Cappell (1975), by Stolerman, Pilcher, and D'Mello (1978), and by Van der Kooy and Phillips (1977). Furthermore, the extent of the CTA varies across rats, and there is concordance in rats' standing with respect to extent of aversion across repeated tests for CTA. These individual differences could conceivably be related to "addiction proneness" of rats as measured by their voluntary intake of sweetened morphine solution. We did not, however, find such a relationship.

It is possible that individual differences in the extent of naloxone CTA do not reflect individual differences in endorphinergic functioning. It has been shown that administration of morphine or an enkephalin analogue potentiates subsequent consumption of sweetened morphine solution (Stapleton, Lind, Merriman, Bozarth, \& Reid, 1979), but this could be a pharmacological effect that is unrelated to endogenous opioid functioning under normal circumstances.

Naloxone injections, given prior to the opportunity to drink, reduce fluid consumption in rats. This robust finding has been shown repeatedly by Frenk and Rogers (1979), by Holtzman (1975, 1979), by Stapleton, Ostrowski, Merriman, Lind, and Reid (1979), in Experiment 1, and in Experiment 2, in which each of the six subgroups showed a reduction in water intake following naloxone injections. This may be related to naloxone's ability to produce a CTA. We did not, however, find a relationship between extent of CTA using naloxone and naloxone's suppression of water consumption. This provides no support for the hypothesis that naloxone's suppression of drinking is due to nonspecific illness-producing effects of the drug. Frenk and Rogers' (1979) data, indicating that lithium chloride produces a CTA but does not suppress drinking, also argue against this hypothesis. Furthermore, treatment with morphine did not modify naloxone's reduction of water consumption. Without question, naloxone leads to reduced water consumption. It remains to be seen whether this finding has relevance for understanding processes of addiction or is a clue to endorphinergic functioning.

\section{REFERENCES}

Coogle, C. L. Naloxone and morphine effects on electrical self-stimulation of the accumbens nucleus in addict and nonaddict rats. Unpublished master's thesis, Rensselaer Polytechnic Institute, 1979.

FrenK, H., \& Rogers, G. H. The suppressant effects of naloxone on food and water intake in the rat. Behavioral and Neural Biology, 1979, 26, 23-40.

Gorman, J. E., DeObaldia, R. N., Scott, R. C., \& Reid, L. D. Morphine injections in the taste aversion paradigm: Extent of aversions and readiness to consume sweetened morphine solutions. Physiological Psychology, 1978, 6, 101-109.

Holtzman, S. G. Effects of narcotic antagonists on fluid intake in the rat. Life Sciences, 1975, 16, 1465-1470.

Holtzman, S. G. Suppression of appetitive behavior in the rat by naloxone: Lack of effect of prior morphine dependence. Life Sciences, 1979, 24, 219-226.

LeBlanc, A. E., \& Cappell, H. Antagonism of morphineinduced aversive conditioning by naloxone. Pharmacology, Biochemistry and Behavior, 1975, 3, 185-188.

Stapleton, J. M., Lind, M. D., Merriman, V. J., Bozarth, M. A., \& REID, L. D. Affective consequences and subsequent effects on morphine self-administration of d-ala ${ }^{2}$-methionine enkephalin. Physiological Psychology, 1979, 7, 146-152.

Stapleton, J. M., Ostrowski, N. L., Merriman, V. J., Lind, M. D., \& REID, L. D. Naloxone reduces fluid consumption in water-deprived and nondeprived rats. Bulletin of the Psychonomic Society, 1979, 13, 237-239.

Stolerman, I. P., Pilcher, C. W. T., \& D’Mello, G. D. Stereospecific aversive property of narcotic antagonists in morphine-free rats. Life Sciences, 1978, 22, 1755-1762.

Van der Kooy, D., \& Phillips, A. G. Temporal analysis of naloxone attenuation of morphine-induced taste aversion. Pharmacology, Biochemistry and Behavior, 1977, 6, 637-641.

(Received for publication July 25, 1979.) 